\title{
CABALLEROS Y LETRADOS. LA APORTACION CIVILISTA A LA ADMINISTRACION CORREGIMENTAL VALENCIANA DURANTE LOS REINADOS DE CARLOS III Y CARLOS IV
}

\author{
Enrique GIMENEZ LOPEZ \\ Universidad de Alicante
}

Una administración territorial como la valenciana, concebida sobre bases de predominio militar, otorgaba a los civiles papeles de segundo rango y, por lo general, subordinados a la autoridad castrense. Las tesis de quienes desaconsejaban la militarización del cargo, señalando sus muchos inconvenientes, como la inadecuación del militar a las funciones corregimentales, o el carácter intemporal de la duración del cargo, y su inmunidad a los controles que otros funcionarios similares soportaban, se fueron abriendo paso dificultosa y lentamente en la segunda mitad de siglo, para retroceder nuevamente en los años noventa, cuando los temores que suscitaron los acontecimientos de Francia y la desaparición de toda una generación reformista, hicieron posible la regresión de las tesis civilistas y el avance de los criterios militaristas hasta posiciones similares a las existentes a fines del reinado de Felipe V.

En cualquier caso, la participación de corregidores civiles en la administración valenciana fue escasa. Sólo las ciudades de Valencia y Castellón contaron con corregidores de capa y espada; la capital entre 1770 y 1797, años en que el corregimiento valenciano estuvo disgregado de la Intendencia; Castellón, por otro lado, durante el paréntesis comprendido entre 1785 y 1791 . Alcira, Alcoy y Jijona pasaron a convertirse en corregimientos de letras en distintos momentos del proceso de reforma de la administración territorial valenciana. Alcira estuvo servida por letrados entre 1768 y 1791, año en que los militares volvieron a hacerse cargo de su corregimiento; Alcoy tuvo corregidor letrado desde 1747, y Jijona desde 1753. Onteniente, por último, tras la supresión del gobierno de alcaldes ordinarios que regía la villa, quedó segregado del corregimiento de San Felipe en 1752, transformándose en corregimiento de letras.

\section{LOS CORREGIDORES DE CAPA Y ESPADA}

Los individuos que sirvieron el corregimiento de la ciudad de Valencia en los veintisiete años comprendidos entre 1770 y 1797, no eran miembros destacados de la carrera corregimental. La concentración de autoridades de mayor rango en la capital 
del reino, desde el Capitán General a la Audiencia, pasando por la Intendencia, y las funciones encomendadas al gobernador militar de la plaza, difuminaban un tanto la figura del corregidor, cuya labor quedaba restringida a la vigilancia y regulación del abasto de un núcleo urbano populoso.

Tras la designación del intendente Andrés Gómez de la Vega como Consejero de Guerra en 1770, fue nombrado nuevo corregidor Diego Navarro Gómez, del que ignoramos los perfiles de su carrera administrativa y del que tan sólo conocemos su origen aragonés, pues era natural de Borja, villa en la que poseía una regiduría perpetua'.

Nuestro conocimiento de su sucesor, Juan Cervera, es algo mayor. Andaluz, la mayor parte de su carrera administrativa se había desarrollado en Sevilla, donde sirvió el cargo de comisario de millones hasta 1770 y diversas comisiones encomendadas por el municipio hispalense. En aquella fecha le fue conferido el corregimiento de Zaragoza, destino desde el que pasó a Valencia en marzo de $1774^{2}$, para regresar a Andalucía como corregidor de Ecija a fines de 1777.

Joaquín Pareja Obregón, su sustituto, es el corregidor civil de Valencia con una más larga trayectoria en la ciudad. Procedía del corregimiento de Murcia cuando pasó a ocupar, por vez primera, el gobierno de la capital del reino de Valencia. Era hombre experimentado, que se había iniciado en la milicia, actividad que abandonó para dedicarse al servicio de corregimientos desde 1758 en que se le destinó al de Linares ${ }^{3}$. $\mathrm{Su}$ primer trienio en Valencia fue juzgado muy favorablemente por los regidores, diputados del común y síndico procurador general, quienes solicitaron su continuidad al frente del corregimiento valenciano para que prosiguiera las iniciativas destinadas al embellecimiento urbano ${ }^{4}$.

Los informes de la Audiencia valenciana le fueron también favorables, estimando conveniente la prórroga del mandato de Pareja "así por la experiencia que ha adquirido en varios asuntos que ha manejado, como por el celo, aplicación e integridad de todos sus procedimientos" 5 , sumándose a la petición el mismo capitán general. Pese a estos apoyos, y al dictamen favorable de la Cámara de Castilla, Carlos III consideró más apropiada su sustitución, siguiendo un modo de hacer que veremos reiterado en otras prórrogas solicitadas en aquellos años por otros corregidores civiles valencianos. Cumplido por su sucesor, Juan Pablo Salvador de Asprer, el preceptivo trienio, Joaquín Pareja fue designado nuevamente corregidor de Valencia por un período de seis años al estar ya vigente la real cédula de 21 de abril de 1783 que ampliaba a un sexenio la duración del oficio ${ }^{6}$, pero a su término le sería prorrogado "en

1 A.H.N. Consejos, Leg. 18.251 : Testimonio de la toma de posesión del corregidor de Valencia. 19 de septiembre de 1770 .

2 A.G.S. Gracia y Justicia, Leg. 161: La Cámara propone para el corregimiento de Capa y Espada de la ciudad de Valencia. 1 de diciembre de 1773.

3 A.G.S. Gracia y Iusticia, Leg. 156: Informe reservado para la provisión del corregimiento de Linares. 1758.

4 A.G.S. Gracia y Justicia, Leg. 163: La Cámara de Castilla. 6 de abril de 1781.

5 A.G.S. Gracia y Justicia, Leg. 163: Informe de la Real Audiencia de Valencia. Valencia, 26 de marzo de 1781 .

6 GONZALEZ ALONSO, Benjamín: El Corregidor castellano (1348-1808). Madrid, 1970, pp. 261-266. Para el nombramiento de Joaquín Pareja, vid. A.H.N. Consejos, Leg. 18.251: Designación del Corregidor de Valencia. 2 de octubre de 1785. 
atención a la antigüedad en la carrera de corregidor', hasta mayo de 1797, fecha de su jubilación 7 . El criterio seguido por Roda de no prorrogar el mandato de los corregidores, y evitar el posible menoscabo de la independencia del funcionario, se abandonó con el consiguiente freno a las reformas propugnadas por el político aragonés.

Como hemos indicado, en el período comprendido entre los dos mandatos de Joaquín de Pareja, desempeñó el corregimiento valenciano Juan Pablo Salvador de Asprer, descendiente de una familia catalana que se mantuvo fiel a Felipe $\mathrm{V}$ durante el conflicto sucesorio y que por ello fue premiada con una regiduría en el concejo municipal de Villafranca del Penedés ${ }^{8}$, en el que el propio Salvador de Asprer ostentaba el cargo de regidor decano. Su carrera en la administración territorial había comenzado en 1764 como corregidor de Hellín ${ }^{9}$, y durante su mandato en Valencia tuvo que enfrentarse a los daños causados por las inundaciones de 1783 y sus desastrosos efectos en la red viaria y en los abastecimientos urbanos ${ }^{10}$.

Tras la jubilación de Pareja y Obregón en mayo de 1797, la fórmula que mantenía independiente al corregidor de Valencia de la Intendencia fue abandonada, lo que suponía renunciar a una de las piezas del entramado reformador de Campomanes - la Real Cédula de 1766-, que perseguía dar un mayor protagonismo a los letrados, "restableciendo las cosas en su orden natural", y separando la administración civil de la militar.

En el corregimiento de Castellón, que también estuvo servido por corregidores de capa y espada, se observa este mismo proceso de retorno a situaciones anteriores a la política reformista de los años sesenta y setenta, ya que su creación coincide cronológicamente con el cenit reformador y el abandono posterior de toda transformación novedosa en el terreno de la administración corregimental. En enero de 1785, un mismo decreto separaba el corregimiento del gobierno militar y designaba para el primero a Mariano Lovera, un caballero de la orden de San Juan ", al que la muerte sorprendió en Castellón antes de poder finalizar su mandato. Su sustituto fue Joaquín de Sandoval, conde de la Ventosa, quien, pese a recibir un corregimiento civil, era militar retirado. Su mandato fue breve, pues si bien recibió su título en junio de 1789 , en marzo de 1791 solicitó su renuncia por enfermedad ${ }^{12}$, un mes más tarde de que un Real Decreto ordenara "que el corregimiento de Castellón sea y se tenga por corregimiento militar y político en la propia conformidad que lo fue antes" 13 .

7 A.H.N. Consejos, Leg. 18.251: Jubilación del corregidor D. Joaquín Pareja Obregón. 19 de mayo de 1797: "...por Decreto de 23 de abril de 1797 he servido con todo el sueldo de 36.000 rs. de vellón que ahora disfruta".

8 TORRAS RIBE, Josep María: Els municipis catalans de l'Antic Règim,1453-1808. Barcelona, 1983 , p. 171.

9 A.G.S. Gracia y Justicia, Leg. 158: Propuestas para el corregimiento de Hellin. 1764.

10 A.G.S. Gracia y Justicia, Leg. 824: Relación jurada de D. Joaquín Pareja y Obregón. Valencia, 13 de diciembre de 1785.

I1 A.H.N. Consejos, Leg. 18.241: Real Decreto de 28 de enero de 1785 para proveer el corregimiento de Castellón como civil y político.

12 A.G.S. Guerra Moderna, Leg. 6.391: El corregidor de Castellón, Conde de la Ventosa, suplica la renuncia del cargo. Madrid, 30 de marzo de 1791.

13 A.H.N. Consejos, Leg. 18.241: Real Decreto de 15 de febrero de 1791 . 


\section{LOS CORREGIDORES LETRADOS}

El carácter profesional de los letrados que actuaron en los corregimientos valencianos viene determinado, hasta cierto punto, por la categoría de las plazas a que fueron destinados. Mientras Alcira y Alcoy pasaban por ser corregimientos de mediano nivel a los que llegaban habitualmente letrados con experiencia en la administración borbónica, Onteniente y Jijona no eran considerados destinos envidiables. En octubre de 1786, el corregimiento de Jijona fue ocupado por el letrado Roque Marín Domínguez, quien no halló aliciente alguno en la ciudad, por lo que durante los ocho meses en que desempeñó el cargo, más de la mitad los vivió fuera del corregimiento, con licencias por asuntos propios o en comisiones oficiales. Su opinión poco amable de Jijona puede resumirse en uno de los párrafos del informe dejado por Marín Domínguez a su sucesor, en cumplimiento del artículo sexto del Reglamento de Corregidores de marzo de 1783, antes de trasladarse a Daroca de donde había sido nombrado nuevo corregidor:

"Todo finalmente presenta a la vista una constitución capaz de aterrar el ánimo más resuelto, pues llamando por sí solo cada uno de tantos objetos, la atención seria y eficaz del gobierno, ni éste se halla con fuerzas y facultades para todos, ni es fácil resolverse en la preferencia de ninguno" ${ }^{14}$.

El caso de Juan Pedro Coronado en Onteniente es todavía más significativo. Este, tras finalizar sus servicios como alcalde mayor de lo civil de Valencia, fue nombrado nuevo corregidor de Onteniente. Sin embargo, no aceptó el cargo al considerarlo inadecuado a los propios méritos acumulados en su carrera administrativa:

"Me es inexcusable poner en consideración de V.S.I. la suma cortedad de
este empleo, que se ejercita en sólo el terreno que comprende la pobla-
ción, ubicada en la profundidad de los más encumbrados montes de este
reino que la circundan y constituyen sumamente fría, y tan pobre que los
más de sus vecinos se ejercitan en el oficio de peraires y cardadores, y se
mantienen con carne de macho, no usándose la de carnero y vaca" 1.5

Los escrúpulos de Coronado hacia Onteniente eran conscientemente exagerados dadas sus expectativas profesionales, ya que pretendía la primera alcaldía mayor de Sevilla o la de Málaga.

La cualificación profesional de algunos corregidores, sobre todo la de los destinados al pequeño corregimiento de Jijona, era discreta y, en algunos casos, se trataba claramente de medianías. Sucede así con José Santonja, Antonio Rodríguez y Pedro Alejandro de Ribera. El primero de ellos, nombrado corregidor en 1776, había iniciado sus contactos con la administración como alcalde mayor en tierras de señorío, respon-

14 A.G.S. Gracia y Justicia, Leg. 825: Relación en que dejo el corregimiento de la ciudad de Jijona. Jijona, 30 de julio de 1786.

15 A.H.N. Consejos, Leg. 18.251: Renuncia de Juan Pedro Coronado al corregimiento de Onteniente. 18 de noviembre de 1763 . 
sabilizándose primero de la vara de Llombay y posteriormente de la de Cofrentes, para servir más tarde el corregimiento de Reinosa, la alcaldía mayor de Alcira en 1761, y la de Villarrobledo en $1767^{16}$. Pese a tan amplio historial, era considerado en el Consejo de Castilla como una mediocridad, si bien cumplidor de sus obligaciones administrativas:

“...aunque en la facultad no era de inteligencia sobresaliente, tenía la bastante para cumplir con su obligación y que, en cuanto a su juicio y buenas costumbres no tenía defecto" ${ }^{17}$.

Una opinión semejante era la que se tenía de Pedro Alejandro Rivera, quien fue designado corregidor en 1769 , si bien no pudo tomar posesión de Jijona hasta mediados de febrero de 1770 por haber quedado enfermo en Villena ${ }^{18}$, cuyo corregimiento había ocupado en 1754 y $1764^{19}$. Antes de servir corregimientos había sido alcalde mayor de lo criminal de Granada y, si bien el Consejo valoraba su honradez, reconocía sus limitaciones:

"...era de pocos alcances, y por consiguiente de limitada literatura, pero era de buen genio, quieto y honrado, y de notoria limpieza y desinterés", 20 .

Menos complacientes son los informes que se hicieron sobre Antonio Rodríguez de Rivera, nombrado en 1794 para Jijona ${ }^{21}$, y que denota la frecuente llegada a ésta de corregidores que no habían sobresalido en la carrera. Con respecto a Rodríguez de Rivera se indicaban las muchas dificultades que encontraba para ascender en el escalafón, y así el decano de la Chancillería de Granada, José de Pineda, señalaba que "Rodríguez carece de las circunstancias que debiera tener para ejercer jurisdicción, pues ni tiene ciencia, conducta, desinterés, ni ha promovido obras públicas", si bien más caritativa era la opinión del obispo de Coria, aunque semejante a la anterior en lo sustancial:

"El citado Rivera es de regular ciencia y aptitud para ejercer su empleo, de honestas costumbres, aunque bastante inclinado a los intereses, y no de mucho celo y actividad en las materias públicas" 22 .

16 A.G.S.: Gracia y Justicia, Leg. 159: Informes reservados para la provisión de la alcaldía mayor de Villarrobledo. 1767.

17 A.G.S. Gracia y Justicia, Leg. 161: La Cámara propone letrados para el corregimiento de la ciudad de Jijona, en el Reino de Valencia. 30 de abril de 1776.

18 A.H.N. Consejos, leg. 18.244: Testimonio de la toma de posesión de D. Pedro Alejandro de Rivera. 17 de febrero de 1770.

19 A.G.S. Gracia y Justicia, Leg. 158: Informe de D. Francisco de Cascajares y Castillo para la provisión del corregimiento de Villena, 1764; y Leg. 158 : Informes reservados para la provisión del corregimiento de Villena, 1754.

20 A.G.S. Gracia y Justicia, Leg. 160: La Cámara propone sujetos para el conegimiento de la ciudad de .Jijona. 21 de junio de 1769.

21 A.H.N. Consejos, Leg. 18.244: Título de corregidor de Jijona a D. Antonio Rodriguez de Rivera. 12 de marzo de 1794.

22 A.G.S. Gracia y Justicia, Leg. 823: Informes reservados sobre Antonio Rodríguez de Rivera. 1785. 
La mayor parte de los letrados fueron castellanos, sobre todo andaluces, vallisoletanos y murcianos, y en menor grado aragoneses. El primer corregidor civil de Alcoy, Gerónimo de las Doblas, era un abogado andaluz que se había iniciado en la carrera administrativa en Algeciras y que posteriormente pasó a Valladolid como alcalde mayor. Sus desavenencias con el corregidor de dicha ciudad aconsejaron su traslado a Alcoy, cuyo mandato fue prorrogado en noviembre de 1750 "en atención al celo y acierto con que D. Gerónimo de las Doblas sirve el Corregimiento de la villa de Alcoy y promueve el adelantamiento de las fábricas que hay en ella" ${ }^{23}$. También era andaluz el corregidor de Alcira Miguel Fernández de Zafra, letrado con amplia experiencia en la carrera, pues cuando llegó a ocupar el corregimiento alcireño en 1779 ya había cumplido dos décadas de servicios en alcaldías y corregimientos. Natural de Antequera, comenzó como alcalde mayor de Jaca, pasando a la alcaldía de Gerona en 1762, y posteriormente a la de Trujillo, y a partir de los años setenta lo encontramos sirviendo los corregimientos de Linares y Avila. Así mismo, eran sevillano y granadino respectivamente los corregidores de Jijona Roque Marín Domínguez y Francisco Castillo Valero ${ }^{24}$.

Otros, de los que desconocemos su origen, habían desempeñado buena parte de sus servicios en tierras andaluzas, regresando nuevamente al Sur tras un breve paréntesis en las de Valencia. Es el caso de Gaspar de Aranda y Villegas, que llegó a corregidor de Alcoy en 1775 con un amplio curriculum iniciado en la alcaldía mayor de Vera en 1751, para seis años más tarde ocupar la de Baeza y posteriormente, en 1762, la de Málaga ${ }^{25}$. Tras su experiencia en alcaldías mayores, al iniciarse la década de los años setenta pasó a servir corregimientos también en Andalucía. En octubre de 1772, el Marqués de Vanmarck, capitán general de Andalucía, intercedió en su favor para que se le otorgasen honores de togado en reconocimiento a su gestión como corregidor de la Isla de León a la que, ante la previsible ruptura con Inglaterra, abasteció y dio alojamiento a la tropa de infantería y caballería a ella destinada ${ }^{26}$. Tras el paréntesis valenciano que supuso su incorporación a Alcoy, y su paso posterior por el corregimiento de Lorca, Aranda y Villega prosiguió su carrera en Andalucía, alcanzando la envidiable alcaldía mayor de Cádiz en $1787^{27}$.

Valladolid en particular y Castilla la Vieja en general también aportaban un número significativo de corregidores letrados a la administración borbónica en Valencia. Manuel Naranjo y Angulo tomó posesión de Jijona en 1780; se trataba de un letrado vallisoletano iniciado en las tareas administrativas cumpliendo comisiones encomendadas por el Consejo de Ordenes, con algunas propuestas frustradas para corregidor de Arévalo y alcalde mayor de Burgos, hasta que en 1775 fue nombrado corregi-

23 A.H.N. Consejos, Leg. 18.238: Decreto prorrogando el corregimiento de Alcoy por otro trienio. 19 de noviembre de 1750 .

24 A.H.N. Consejos, Leg. 18.244: Título de Corrregidor de Jijona a Francisco del Castillo Valero. 8 de diciembre de 1806.

25 A.G.S. Gracia y Justicia, Leg. 158: Informes para la provisión de la alcaldía mayor de Málaga. 1762.

26 A.G.S. Gracia y Justicia, Leg. 819: Marqués de Vanmarck a Manuel de Roda. Puerto de Santa María, 10 de octubre de 1772. 1787.

27 A.G.S.: Gracia y Justicia, Leg. 822: Informes reservados sobre Gaspar Aranda y Villegas. 
dor de Madrigal, de donde pasó a Jijona ${ }^{28}$. También procedía de Valladolid el corregidor de Alcoy Juan Bermejo, el último de los corregidores alcoyanos antes de los cambios políticos producidos por la conmoción de la Guerra de la Independencia ${ }^{29}$; y Jacinto Javier Castro, licenciado en derecho por la Universidad de Valladolid, si bien se había doctorado en leyes en la Universidad de Gandía, dada la facilidad con que estas universidades convalidaban estudios y concedían el grado de doctor. Jijona fue el primer destino en la carrera de Jacinto Javier de Castro, ya que su experiencia anterior se limitaba a comisiones encomendadas por la Audiencia de Valencia, a actuar de auditor interino de Marina del departamento de Valencia, y a la alcaldía mayor de Novelda, en tierras de señorío ${ }^{30}$.

Murcianos eran Pedro Moscoso y Figueroa y Agustín Lozano, entre otros. El primero fue corregidor de Alcira entre 1772 y 1775, y el segundo de Alcoy entre 1764 y 1768. Pedro Moscoso era un letrado, hijo de militar, formado en el colegio de San Fulgencio de Murcia, institución que años más tarde sería importante foco de ideas ilustradas ${ }^{31}$, y que había ejercido la abogacía en Madrid hasta 1757, en que fue destinado a servir el corregimiento de Villena ${ }^{32}$. Posteriormente desempeñó las alcaldías mayores de San Felipe y Ecija y, en 1768, el corregimiento de Andújar, obteniendo siempre informes muy favorables del Consejo sobre su gestión ${ }^{33}$. Agustín Lozano Avellán había sido colegial de la Anunciata, y había comenzado ocupándose de las varas de Tobarra e Iniesta, en Cuenca, tras lo que fue designado en 1745, y por vez primera, para corregidor de Villena ${ }^{34}$, donde volvería en 1761 tras su paso por el corregimiento aragonés de Tarazona.

Entre los letrados aragoneses localizados se encuentran Pedro de Rivas y Antonio Sobrecasas. Pedro de Rivas García Infanzón era natural de Daroca y entre 1775 y 1778 fue corregidor de Alcira. Con estudios de leyes en Sigüenza y Alcalá, Rivas había ejercido la abogacía en su Daroca natal y en Madrid entre 1741 y 1760 ; en diciembre de este último año inició su carrera administrativa en Aragón, como alcalde mayor de lo criminal de Zaragoza, prosiguiéndola en aquel reino como corregidor de Benavarre y alcalde mayor de Zaragoza entre 1768 y su traslado a Alcira en $1775^{35}$. Antonio Sobrecasas, si bien natural de Huesca, en cuya universidad realizó sus estudios de leyes, estuvo estrechamente vinculado a la realidad administrativa valenciana.

28 A.G.S. : Gracia y Justicia, Leg. 162: La Cámara propone para el corregimiento de Letras de la ciudad de Jijona. 29 de febrero de 1780.

29 A.H.N. Consejos, Leg. 18.238: Propuesta de la Cámara para el c'orregimiento de Alcoy. 13 de febrero de 1808 .

30 A.G.S. Gracia y Justicia, Leg. 161: La Cámara propone para el corregimiento de letras de la ciudad de Jijona. 17 de marzo de 1773.

31 MAS GALVAÑ, Cayetano: "Jansenismo y regalismo en el Seminario de San Fulgencio de Murcia", en Anales de la Universidad de Alicante. Historia Moderna, 2 (1982), pp. 259-290.

32 A.G.S. Gracia y Justicia, Leg. 155: Informes para la provisión del corregimiento de Villena. 1757 .

33 A.G.S. Gracia y Justicia, Leg. 159: Informe del Conde de la Villanueva para proveer el corregimiento de Ecija, 1767.

34 A.G.S. Gracia y Justicia, Leg. 149: Informes reservados para la provisión del corregimiento de Villena. 1745.

35 A.H.N. Consejos, Leg. 18.237: Relación de los méritos y servicios del licenciado D. Pedro de Rivas Garcia Infanzón. 21 de junio de 1774. 
Cuando fue designado en 1770 nuevo corregidor de Onteniente ${ }^{36}$, acababa de desempeñar la alcaldía mayor de Orihuela, y su experiencia y, sobre todo, el conocimiento que poseía de la realidad valenciana fueron determinantes en su elección. Tras sus estudios en la universidad oscense, Sobrecasas había pasado a Valencia encargado por el Consejo de tomar residencias en Alicante y Orihuela, ocupando interinamente la alcaldía mayor de la última durante siete meses. Su breve gestión en Orihuela fue considerada muy eficiente, y en 1765 fue designado corregidor de Jijona en atención a que "en el Consejo no se han oído quejas, lo que prueba su prudencia por los genios de Alicante y Orihuela, cuyos pueblos son populosos y los más vivos y delicados del reino" " ${ }^{37}$. No tomó posesión de Jijona, ya que el obispo de Orihuela, Pedro Albornoz y Tapia, un valenciano discípulo del arzobispo Mayoral, y con excelentes relaciones con el Consejo de Castilla, se interesó para que ocupara la alcaldía mayor de la ciudad episcopal, de donde pasó en 1770 a Onteniente como corregidor ${ }^{38}$.

Los corregidores valencianos eran escasos. Sólo tenemos la certidumbre de Máximo Terol y Domenech, natural de Muchamiel, población huertana cercana a Alicante, y Francisco Berdún Espinosa, originario de Gandía, y uno de los letrados con más dilatados servicios en tierras valencianas. Máximo Terol fue el último de los corregidores civiles que sirvieron el corregimiento alcireño; tomó posesión de su nuevo destino el 7 de enero de 1784, procedente del corregimiento de Borja, en Aragón, si bien su carrera se inició como alcalde mayor de Morella en 1765, de donde había pasado a Cataluña a servir la vara de Camprodón ${ }^{39}$. Francisco Berdún, por su parte, había realizado estudios de derecho en la universidad de Gandía y se hallaba muy vinculado con la administración valenciana, pues fue alcalde mayor de Valencia, en dos ocasiones corregidor de Alcoy, y en una corregidor de Alcira y Onteniente. Berdún había ejercido pasantías en Madrid hasta que en 1737 fue nombrado alcalde mayor de Valencia ${ }^{40}$, con el apoyo del gobernador del Consejo de Castilla, el cardenal Molina, que se refería a él en los siguientes términos: "Yo le tengo por uno de los ministros más limpios, desinteresados y celosos del bien público" "1 . Tras pasar por la alcaldía mayor de Badajoz fue designado en 1754 para ocuparse del corregimiento alcoyano ${ }^{42}$, y mantuvo el buen crédito que tenía en el Consejo al ser prorrogado su mandato en 1757 "atendiendo a lo bien que desempeña su obligación" 43 . En marzo de 1761 fue

36 A.H.N. Consejos, Leg. 18.246: Título de corregidor a D. Antonio Sobrecasas. 23 de octubre de 1770 .

37 A.G.S. Gracia y Justicia, Leg. 159: Testimonios reservados para la provisión del corregimiento de Jijona. 1765.

38 A.G.S. Gracia y Justicia, Leg. 160: Corregimiento de letras de la villa de Onteniente, vacante por haber cumplido su trienio D. Bernardo Falceto. 1770.

39 A.H.N. Consejos, Leg. 18.540: Testimonio de la toma de posesión del alcalde mayor de Camprodón. 20 de junio de 1770 .

40 A.G.S. Gracia y Justicia, Leg. 845: Relación de méritos del doctor D. Francisco Berdún Espinosa. 12 de julio de 1740.

41 A.G.S. Gracia y Justicia, Leg. 845: El Cardenal de Molina al Marqués de Villarias. Madrid, 5 de noviembre de 1741 .

42 A.H.N. Consejos, Leg. 18.238: Testimonio de la toma de posesión del corregidor de Alcoy. Alcoy, 16 de agosto de 1754 .

43 A.H.N. Consejos, Leg. 18.238: Real Despacho prorrogando el corregimiento de Alcoy. 15 de febrero de 1757. 
nombrado corregidor de Onteniente ${ }^{44}$, y tras un mandato en Zaragoza como alcalde mayor le fue encomendado el corregimiento de Alcira, que, por decreto de 9 de febrero de 1768, había pasado a ser corregimiento de letras. Por tanto Francisco Berdún, al tomar posesión de su cargo el 15 de octubre de 1768, se convirtió en el primer corregidor letrado de Alcira ${ }^{45}$. Al finalizar su trienio, el ayuntamiento alcireño realizó gestiones para que se le prorrogase su mandato, al considerar que con él la villa "experimenta un gobierno político equilibrado y ventajoso", sumándose a dicha petición el clero regular y secular ${ }^{46}$. EI capitán general también manifestó su apoyo a la iniciativa alcireña por el acierto con que Berdún había realizado la leva para el reemplazo del ejército, y la Audiencia informó favorablemente "por lo que le consta del buen procedimiento en la administración de justicia" 47 . Sin embargo, Campomanes consideró que debía ser norma de la Cámara no acceder a las solicitudes de prórroga, por muy justificadas que estuvieran las peticiones, si bien el período trienal debía ampliarse a un sexenio, como proyectaba el mismo Campomanes en su modelo de reforma corregimental: "Que a todos los corregimientos del reino convendría por punto general mayor duración que la que actualmente tiene" 48 .

La resolución real, fechada el 7 de febrero de 1772, aceptó la recomendación de la Cámara y denegó la prórroga, designando a Berdún para un nuevo mandato en Alcoy un mes más tarde, si bien el consejero de Castilla Arias Campomanes lo recomendó vivamente para una plaza de magistrado en alguna Audiencia "por su aplicación, celo, inteligencia, desinterés y antigüedad" 49.

El conocimiento del reino de Valencia era considerado por el Consejo un elemento a valorar positivamente a la hora de proponer letrados para ocupar vacantías. Joaquín Anaya, corregidor de Alcoy, había sido con anterioridad alcalde mayor de Alicante; en 1795 fue nombrado para ese mismo corregimiento Antonio Roca y Huertas, quien en 1787 había tomado su primer destino en el corregimiento de Jijona. Ya hemos indicado anteriormente que Antonio Sobrecasas había sido alcalde mayor de Orihuela antes de pasar a Onteniente como corregidor; a mediados de 1790 fue corregidor de esa misma villa Francisco Tabuenca, quien acababa de finalizar su estancia en Morella como alcalde mayor ${ }^{50}$, si bien un "accidente apoplégico" le obligó a renunciar al corregimiento en los primeros meses de 1795, señalándole la Cámara una

44 A.H.N. Consejos, Leg. 18.238: Real Decreto designando corregidor de Alcoy. 7 de marzo de 1754.

45 Por decreto de 9 de febrero de 1768 se dio un paso más en la reforma de los corregimientos valencianos al disponer que, cumplido el trienio del ya coronel Juan José de Sada, el corregimiento alcireño fuera servido por un letrado. Ante la proximidad de su cese, Sada solicitó el abono de 12.000 rs. anuales desde el momento de su salida del corregimiento hasta que se le concediera un destino acorde con su graduación, lo que le fue denegado terminantemente. Vid. A.G.S. Guerra Moderna, Leg. 1.380 : Juan José de Sada a Juan Gregorio Muniáin. Alcira, 27 de abril de 1768.

46 A.H.N. Consejos, Leg. 18.237: Expediente del Ayuntamiento de la villa de Alcira sobre que a D. Francisco Berdún de Espinosa se le prorrogue en el empleo de corregidor de ella por otro trienio. 1771 .

47 A.H.N. Consejos, Leg. 18.237: Ibídem.

48 A.H.N. Consejos, Leg. 18.237: Cámara de Castilla, 18 de enero de 1772.

49 A.G.S. Gracia y Justicia, Leg. 160: La Cámara propone para el corregimiento de letras de Alcoy en Valencia. 1 de abril de 1772.

50 A.H.N. Consejos, Leg. 18.246: Título de corregidor de Onteniente a D. Francisco Tabuena. 7 de noviembre de 1790. 
pensión de jubilación de 200 ducados anuales ${ }^{51}$; Bernardo Cebasco y Rosete cuando fue nombrado en 1801 corregidor de Alcoy, era hombre de edad madura, que había cumplido los sesenta años, y procedía de la alcaldía mayor de San Felipe ${ }^{52}$; y Juan Francisco Bernal, corregidor de Jijona desde marzo de 1766, y anteriormente alcalde mayor de Alcira, quien a decir del consejero de Castilla Pedro Ric era hombre "de genio duro y poco suave" 53 .

Un elemento común de muchos de estos letrados es su promoción hasta un corregimiento tras largos servicios como alcaldes mayores. En algunos casos se trataba del primer destino corregimental después de haber pasado por numerosas alcaldías mayores, como sucede en los casos de Joaquín Anaya, Atilano Acevedo y Ramón Lanes. Así, Anaya y Aragonés, quien tomó posesión del corregimiento alcoyano en junio de 1761, había servido las alcaldías mayores de Avila, Cuenca, Yecla, Almansa, San Clemente y la de Alicante ${ }^{54}$, y tras Alcoy prosiguió su carrera, ya como corregidor, en Requena y Huete. En el caso de Atilano Acevedo y Herrera, nombrado corregidor de Onteniente en abril de $1774{ }^{55}$, su experiencia anterior se había desarrollado también en alcaldías mayores, como las de Segovia, Sevilla, Carmona y Ciudad Rodrigo ${ }^{56}$, pero no contaba con mucho crédito en el Consejo por considerarlo excesivamente ingenuo: "Era bien intencionado y deseoso del acierto, pero de excesiva bondad, por lo que se fiaba demasiado de los escribanos y subalternos que le asistían" ${ }^{57}$.

Ramón Lanes, también corregidor de Onteniente, aunque sólo por unos meses, había servido alcaldías mayores en los territorios de la antigua corona aragonesa, ya que lo había hecho en Villafranca del Penedés, Lérida, Montblanch y Daroca ${ }^{58}$.

Hay casos en que el ascenso a uno de estos modestos corregimientos valencianos se produce después de haber cumplido con acierto una alcaldía mayor de importancia, como sucede en los casos de Juan Romualdo Jiménez, designado corregidor de Alcoy en 1790 pese a no figurar en la terna consultada por la Cámara, y que había servido con acierto la alcaldía mayor de León, o en los de Lorenzo Ramos y Gerónimo Sirvent Fernández de Vicuña, corregidores de Onteniente en 1752 y 1804, y originarios ambos de la alcaldía mayor de Cartagena ${ }^{59}$.

En ocasiones su procedencia era de corregimientos de menor o semejante entidad. Andrés Angel Durán, nuevo corregidor alcoyano en 1768, procedía del corregi-

51 A.H.N. Consejos, Leg. 18.246 Cámara de Castilla. 11 de abril de 1795.

52 A.G.S. Gracia y Justicia, Leg. 823: Informes reservados sobre D. Bernardo Cebasco. 1801.

53 A.G.S. Gracia y Justicia, Leg. 158: Informe reservado de D. Pedro Ric para la provisión de la alcaldía mayor de Aina. 1761.

54 A.G.S. Gracia y Justicia, Leg. 159: Informes reservados del Consejero de Castilla D. Pedro Castilla para la provisión del corregimiento de Huete. 1768.

55 A.H.N. Consejos, Leg. 18.246: Título de corregidor de Onteniente. 17 de abril de 1774.

56 A.G.S. Gracia y Justicia, Leg. 158: Testimonios para proveer la alcaldia mayor de Carmona. 1763.

57 A.G.S. Gracia y Justicia, Leg. 161: Corregimiento de letras de la villa de Onteniente, vacante por haber cumplido su trienio D. Antonio Sobrecasas, 1774. En el documento se reproduce un informe redactado por el Consejero de Castilla Lope de Sierra en 1761 sobre Atilano Acevedo.

58 A.G.S. Gracia y Justicia, Leg. 159: Informes para la provisión de la alcaldía mayor de Lérida. 1767.

59 A.H.N. Consejos, Leg. 18.246: Título de corregidor de Onteniente a D. Gerónimo Sirvent Fernández de Vicuña. 24 de enero de 1804. 
miento de Reinosa, en Cantabria ${ }^{60}$, y a sus cuarenta y cuatro años de edad había sido alcalde mayor de Alfaro y Calahorra, y contaba con buenos informes del Consejo de Castilla por su condición de hidalgo y por ser "desinteresado y de buenas circunstancias para la judicatura, y posee más de mediana literatura", en opinión del consejero Andrés de Valcárcel Dato ${ }^{61}$; Antonio Párraga Vargas, corregidor de Onteniente en 1756, era un abogado andaluz que se había iniciado en el corregimiento de Villena tras una corta experiencia en la administración señorial, y que tras pasar por el corregimiento de Utrera había sido enviado a tierras valencianas ${ }^{62}$; el también corregidor de Onteniente en 1763, Francisco Alvaro ${ }^{6.3}$, había sido anteriormente corregidor de Betanzos ${ }^{64}$; y Antonio de Anguiozar y Velasco, nombrado corregidor de Alcoy en 1778, pese a no haber sido propuesto por la Cámara ${ }^{65}$, había sido anteriormente alcalde mayor de Alfaro y corregidor de Agreda desde 1776, de donde pasó a Alcoy ${ }^{66}$.

En dos casos de los estudiados se explicita claramente en la documentación que en el nombramiento para corregidor influyó decisivamente su participación en el extrañamiento de la Compañía de Jesús. Tras el mandato de Atilano de Acevedo en Onteniente, fue designado Francisco Ignacio de Moradillo, quien tomó posesión en abril de $1778{ }^{67}$. Moradillo era doctor en Cánones por la universidad de Alcalá, a cuyo claustro había estado vinculado como profesor. Su apoyo entusiasta a la expulsión fue premiado por la Cámara teniéndolo presente en diversas consultas para cubrir plaza de magistrado en la Audiencia de Zaragoza o en el corregimiento de Guadix, hasta su nombramiento para el de Onteniente ${ }^{68}$; Rivas Infanzón tuvo una destacada participación en la expulsión de los jesuitas de su colegio en Graus, y él mismo consideraba que su ascenso a la alcaldía mayor de Zaragoza se debía a su actitud claramente antijesuítica ${ }^{69}$, y así se hacía constar en 1775 por la misma Cámara al proponerlo como

60 A.H.N. Consejos, Leg. 18.238 : Título de corregidor de Alcoy a D. Andrés Angel Durán. 20 de noviembre de 1768 .

61 A.G.S. Gracia y Justicia, Leg. 157: Provisión de la alcaldía mayor de Calahorra. 1760.

62 A.G.S. Gracia y Justicia, Leg. 144: Informes reservados para el correginiento de Villena. 1735. Antonio Párraga y Vargas era hermano de Tomás Párraga, que había sido alcalde mayor de Jaca y corregidor de Albarracín en 1746. Vid. A.G.S. Gracia y Justicia, Leg. 149: Informes reservados para proveer el corregimiento de Albarracín. 1746.

63 A.H.N. Consejos, Leg. 18.246: Real decreto designando corregidor de Onteniente. 18 de noviembre de 1763 .

64 A.G.S. Gracia y Justicia, Leg. 152: Testimonio sobre propuestos para el corregimiento de Betanzos. 1751 .

65 En 1778 ninguno de los tres letrados propuestos por la Cámara de Castilla al Rey fue designado para hacerse cargo del corregimiento alcoyano. Los propuestos eran: 1) Antonio de Andrés González, 2) Juan Bautista Font, 3) Máximo Terol y Domenech. Vid. A.H.N. Consejos, Leg. 18.238: Propuesta de la Cámara para corregidor de Alcoy. 16 de junio de 1778.

66 A.G.S. Gracia y Iusticia, Leg. 162: La Cámara de Castilla, 16 de junio de 1778.

67 A.H.N. Consejos, Leg. 18.246: Testimonio de la toma de posesión del corregimiento de Onteniente D. Francisco Ignacio de Moradillo. 25 de abril de 1778.

68 A.G.S. Gracia y Justicia, Leg. 162: La Cámara de Castilla propone letrados para el corregimiento de la villa de Onteniente. 26 de noviembre de 1777.

69 A.H.N. Consejos, Leg. 18.237: Relación de los méritos y servicios del licenciado D. Pedro de Rivas García Infanzón. 21 de junio de 1774. Pese a señalar como decisiva en su carrera su intervención en Graus para expulsar a los Jesuitas, los inicios de su carrera estuvieron vinculados a su puesto de secretario del Duque de Vistahermosa, por cuyo medio logró su primer cargo en Zaragoza. A.G.S. Gracia y Justicia, Leg. 157: Informe reservado del Consejero de Castilla José Aparicio para la provisión de la alcaldía mayor de to criminal de Zaragoza. 1760. 
candidato a ocupar el corregimiento de Alcira: “... en atención a sus méritos, y especialmente al que hizo en la comisión del extrañamiento y ocupación de temporalidades de los regulares expulsos del colegio de la villa de Graus" 70.

La escasa entidad de Jijona le confería las características de primer destino para muchos letrados que se iniciaban en la carrera corregimental, y de hecho fue clasificada como corregimiento de entrada, o de primera clase, en las disposiciones de 1783. Su primer corregidor letrado, tras la muerte del brigadier Corbí y el abandono del proyecto de unirlo a la ciudad de Alicante, con la asistencia de tan sólo un alcalde mayor designado por el gobernador de la plaza marítima, fue Juan Bautista Ruiz Delgado, quien venía desempeñando en Jijona el cargo de alcalde mayor ${ }^{71}$. El mandato de Ruiz Delgado fue prorrogado un nuevo trienio en junio de 1756, y posteriormente prosiguió su carrera en Aragón como alcalde mayor de Calatayud ${ }^{72}$ y corregidor de Tarazona ${ }^{73}$. También fue Jijona el primer destino del sucesor de Ruiz Delgado, José Cano de Santayana, que durante algún tiempo había actuado en la ciudad como corregidor interino $^{74}$, y de Antonio Sobrecasas, Juan José Pérez y Antonio Roca y Huertas. Durante su mandato, Roca y Huertas procuró mejorar las comunicaciones de Jijona con Alicante y acabar así con el aislamiento de la población, causa de su escasa entidad así como del reducido atractivo que suponía para aquellos letrados encargados de su corregimiento:

"Todo el esmero debe fijarse en verificar la construcción del camino, pues de este modo se conseguirá que los naturales sean sociables, que aprendan educación y que destierren la barbarie, la vanidad y otros entusiasmos quijotescos de que sin razón, causa ni motivo están ahora poseídos, llamando con estas ridiculeces la atención de los pueblos de las inmediaciones", 75 .

En la tipología de los corregidores letrados que hemos ido configurando por los datos que hemos ofrecido, la excepción la aporta Roque Marín de Domínguez, corregidor de Jijona desde octubre de 1786 a mediados a 1787, y al que nos hemos referido con anterioridad para señalar su rechazo al destino que se le había asignado. Ciertamente, Roque Marín se aparta del tipo de letrado modesto, sin apoyos consistentes en el Consejo, o primerizo en la carrera, que sirvió en Jijona. A su larga trayectoria en la administración territorial se sumaba su pertenencia a una conocida familia que contaba

70 A.G.S. Gracia y Justicia, Leg. 161: La Cámara propone sujetos para el corregimiento de letras de la villa de Alcira. 5 de julio de 1775.

71 A.H.N. Consejos, Leg. 18.244 : Real decreto designado corregimiento de letras para la ciudad de Jijona. 12 de julio de 1753.

72 A.G.S. Gracia y Justicia, Leg. 158: Informes para la provisión de la alcaldía mayor de Calatayud. 1762.

73 A.G.S. Gracia y Justicia, Leg. 159: Informes reservados para la provisión del corregimiento de Tarazona. 1768 .

74 A.H.N. Consejos, Leg. 18.244: Título de corrregidor de Jijona a D. José Cano de Santayana. 25 de marzo de 1762.

75 A.H.N. Consejos, Leg. 18.238: Relación jurada que yo, D. Antonio Roca y Huertas, corregidor de la ciudad de Jijona, formo para entregar a mi sucesor. Jijona, 18 de febrero de 1794. 
con destacados servidores del Estado ${ }^{76}$, pues era sobrino de José Manuel Domínguez, consejero de Hacienda y, posteriormente, de Castilla, y cuñado de Juan Gregorio Muniáin, Secretario de Guerra ${ }^{77}$. Desconocemos los motivos que le llevaron hasta Jijona, ciudad en la que no residió en los pocos meses de su mandato, pero sus gestiones en la Corte tuvieron éxito, ya que fue trasladado a la alcaldía mayor de Alicante cuando no había transcurrido medio año desde su toma de posesión.

Las relaciones de estos letrados con las poblaciones de sus corregimientos, y especialmente con las oligarquías locales, fueron menos conflictivas que las protagonizadas por los corregidores militares.

Muchas solicitudes de prórroga fueron realizadas por los propios municipios, que destacaban la gestión positiva del corregidor y la sintonía con las autoridades locales, como sucedió en los casos de Ruiz Delgado en Jijona, Francisco Berdún y Máximo Terol en Alcira, Gerónimo Doblas, Juan Romualdo Giménez o Antonio Roca en Alcoy, y Lorenzo Ramos y Francisco Ignacio de Moradillo en Onteniente. Pero no faltaron conflictos de muy variada índole, especialmente en su relación con grupos de oposición al poder municipal establecido, o con oligarquías locales contrarias a cualquier medida que supusiera una merma de su influencia.

Un ejemplo del primer supuesto lo encontramos en Alcira, al finalizar su trienio el corregidor Pedro de Rivas García Infanzón en 1778. Pedro de Rivas elevó una solicitud de prórroga, y el capitán general de Valencia apoyó la demanda, informando que había logrado establecer una fábrica de mantas sirviéndose de los desperdicios de la seda, y que había construido un cuartel de caballería para alojamiento de la tropa en tránsito ${ }^{78}$. Sin embargo, la concesión de prórroga encontró una fuerte, aunque al parecer minoritaria, oposición entre algunos vecinos de Alcira, quienes llegaron a constituir un grupo de opinión, celebrando reuniones clandestinas y desarrollando un activo proselitismo.

Desconocemos el fondo del asunto, pues cada una de las partes acusó a la contraria con los consabidos argumentos: los vecinos opuestos al corregidor se consideraban "oprimidos con improperio bajo el yugo del predominio con que se les aflige'" 79, el corregidor, considerándose calumniado, lo reducía todo a venganzas personales debidas a su estricta actitud en la aplicación de la justicia ${ }^{80}$. Pero la cualificación de los instigadores de la oposición a Rivas y de quienes lo apoyaban resulta sobremanera ilustrativa: los firmantes del memorial eran un labrador acomodado, un comerciante y un maestro carpintero, y lo que el corregidor señalaba como "cabezas y autores del monstruo de la iniquidad y de esta especie de turbulencia capaz de conster-

76 En la década de 1750, Marín Dominguez había servido la alcaldía mayor de Fregenal de la Sierra, y en los años sesenta le fueron conferidos el corregimiento de Tarazona y la alcaldía mayor de Ecija. A.G.S. Gracia y Justicia, Leg. 158: Consulta para el corregimiento de Tarazona, Madrigueras y Quintanar, 1764 ; y Leg. 159: Informes para proveer la alcaldía nayor de Ecija, 1768.

77 FAYARD, Janine: Los ministros del Consejo Real de Castilla (1621-1788). Informes biográficos. Madrid, 1982. p. 185.

78 A.H.N. Consejos, Leg. 18.237: El capitán general de Valencia informa de la solicitud de prorroga del corregidor de Alcira. 26 de junio de 1778.

79 A.H.N. Consejos, Leg. 18.237: Memorial de vecinos de Alcira solicitando se deniegue la prórroga al corregidor. 19 de septiembre de 1778.

80 A.H.N. Consejos, Leg. 18.237: Memorial del corregidor de Alcira Pedro de Rivas. 27 de septiembre de 1778 . 
nar al pueblo más tranquilo", eran un abogado y un boticario, este último Diputado del Común; el corregidor se hallaba apoyado por los regidores. Todo parece apuntar a que la oposición al corregidor procedía de grupos contrarios a quienes poseían de manera vitalicia los cargos municipales y que habían hallado en la reforma de 1766 un resquicio por el que acceder a una pequeña parcela de poder municipal que pronto se mostraría insuficiente. En el caso que nos ocupa, la Cámara de Castilla dictaminó favorablemente la prórroga solicitada ${ }^{81}$, pero ésta fue denegada por una resolución que sostenía el criterio de no conceder prórrogas a los corregidores una vez concluido su mandato trienal.

En el mismo contexto cabe referirse al conflicto que enfrentó al corregidor de Alcoy, Antonio de Anguionaz y Velasco, con miembros relevantes de la oligarquía alcoyana, como los Puigmoltó, Descals, Merita y Sempere, regidores por línea directa desde 1709 a $1812^{82}$. En este caso el corregidor no se alinea con los regidores, cerrando filas frente a apetencias de poder de grupos excluidos del poder municipal, y es por ello objeto de un claro intento de descalificación. En 1780 los regidores, encabezados por Joaquín Merita, Agustín Puigmoltó, Rafael Descals y Vicente Moltó, decidieron capitular al corregidor Anguionaz, acusándole de haberse expresado calumniosamente contra el conde de Ricla, Secretario de Guerra. Esta actitud tenía su origen en la decisión del Concejo alcoyano de presentar recurso al Consejo de Castilla sobre los perjuicios que sufría la villa por los problemas de alojamiento y del suministro de raciones de pan, cebada y paja que causaban los militares comisionados por sus respectivos cuerpos para contratar vestuario a los fabricantes de paños que pretendían, sin lograrlo, acceder al gobierno municipal ${ }^{83}$.

El corregidor no secundaba esta posición de los regidores alcoyanos que entorpecía la consolidación económica, y por ende política, de los fabricantes agremiados en la Real Fábrica de Paños, y ésta era la razón por lo que fue denunciado. Según sus acusadores, Anguionaz había llegado a afirmar que el Conde de Ricla tenía oscuros intereses en la contratación de uniformes a la Real Fábrica de Paños alcoyana ${ }^{84}$. El capitán general, Marqués de Croix, defendió sin reservas al corregidor, víctima, según él, de un complot. Entre el 18 y el 29 de marzo de 1780, Croix remitió tres escritos al Conde de Ricla: en el primero consideraba despreciables las acusaciones que se le hacían al corregidor ${ }^{85}$; en el segundo, advertía que las quejas de los regidores eran fruto de un resentimiento hacia Anguionaz por haber encarcelado a un hijo del regidor Joaquín Merita y a un cuñado del también regidor Rafael Descals, y por mantener una posición independiente hacia la poderosa oligarquía alcoyana ${ }^{86}$; en el tercero, la defensa del capitán general se hacía más enérgica, hasta el punto de solicitar para el

81 A.H.N. Consejos, Leg. 18.237: Cámara de Castilla, 4 de noviembre de 1778.

82 ROMEO MATEO, María Cruz: Realengo y Municipio: marco de formación de una burguesía (Alcoi en el siglo XVIII). Alicante, 1986, pp. 85-110.

83 Lo tuvieron vedado hasta la Real Orden de 19 de enero de 1785. de 1780 .

84 A.G.S. Guerra Moderna, Leg. 1.385: Regidores de Alcoy al Conde de Ricla. Alcoy, 2 de abril

85 A.G.S. Guerra Moderna, Leg. 1.385: El Marqués de Croix al Conde de Ricla. Valencia, 18 de marzo de 1780.

86 A.G.S. Guerra Moderna, Leg. 1.385: El Marqués de Croix al Conde de Ricla. Valencia, 21 de marzo de 1780 . 
corregidor capitulado una plaza de oidor en la Audiencia valenciana que había dejado vacante el magistrado Luis Alvarez de Mendieta, "en premio a sus persecuciones, en honor de la recta administración de justicia y para evitar la ruina de un juez a quien considero idóneo, de habilidad, literatura y desempeño de la Real confianza de esta Audiencia" 87.

El respaldo al corregidor por las autoridades valencianas era norma cuando se enfrentaba a los regidores, pues desautorizar la autoridad delegada del rey en el territorio iba contra los supuestos de jerarquía que informaban toda la estructura de poder en el estado borbónico. Cuando José Cano de Santayana, corregidor de Jijona desde 1762, pretendió un nuevo mandato encontró la oposición de los regidores y del clero regular afincado en la ciudad, quienes solicitaron su traslado a otro lugar para "el amparo y alivio de tantas tropelías como dicho corregidor ha ejecutado" 88 ; otros apoyaron la continuidad del corregidor, como el síndico procurador general y los ayuntamientos de las poblaciones de corregimiento: Elche, Biar, Tibi, Onil, Ibi, Castalla y Salinas ${ }^{89}$. Finalmente, la prórroga no le fue concedida, si bien el Conde de Aranda, como capitán general, informó favorablemente sobre Cano de Santayana cuando éste pretendió en 1768 el corregimiento de Medina, que finalmente obtuvo ${ }^{90}$.

Una situación semejante se produjo en Alcira en 1782. Cumplido su trienio en aquella villa, Miguel Fernández de Zafra solicitó prórroga, pese a que sus relaciones con las autoridades locales no eran buenas, sobre todo con el regidor decano Baltasar Peris. La Audiencia valenciana apoyó al corregidor "l y la Cámara de Castilla valoró positivamente su labor con los damnificados por las inundaciones de octubre de 1779, las obras públicas realizadas durante su trienio, y la forma en que realizó la leva de $1783^{\circ 2}$, y propuso también su continuidad, si bien, como era norma en aquellos años fue denegada por resolución real de 14 de junio de 1783 .

La contribución civil a la administración territorial valenciana fue escasa, pese a los esfuerzos e interés de la Cámara de Castilla por lograr una mayor implantación jurisdiccionalista. Sólo fue posible sustituir a los oficiales militares de aquellos corregimientos de menor entidad, y esta característica motivó que los letrados que los sirvie-

87 A.G.S. Guerra Moderna, Leg. 1.385 : El marqués de Croix al conde de Ricla. Valencia, 29 de marzo de 1780. Antes de cumplir su trienio, Anguionaz llevó su conflicto con los regidores que le habían capitulado a abusar de su autoridad y encausar al regidor Puigmoltó por estafador en la recaudación del equivalente. la investigación llevaba a cabo por Juan Antonio Disdier de Villagrasa, oficial de la contaduría de propios y arbitrios del reino de Valencia, comisionado por el intendente, demostró que el corregidor había procedido injustamente, y declaró al regidor Puigmoltó libre del delito de estafa, señalando "los excesos, tropelías, violencias y medios injustos de que se ha valido el corregidor D. Antonio Anguionaz y Velasco para perder a Puigmoltó por odio y mala voluntad". Vid. A.G.S. Secretaría de Hacienda, Leg. 580: El Intendente de Valencia sobre excesos cometidos por el corregidor de Alcoy.

1765.

88 A.H.N. Consejos, Leg. 18.244: El concejo de Jijona a Nicolás Manzano. Jijona, 28 de marzo de

89 A.H.N. Consejos, Leg. 18.244: Testimonios para la prórroga de D. José Cano de Santayana. 1765.

90 A.G.S. Gracia y Justicia, Leg. 159: Informe del Conde de Aranda para la provisión del corregimiento de Medina del Campo. 1768.

91 A.H.N. Consejos, Leg. 18.237: Informe de la Audiencia de Valencia sobre la próroga que solicita Miguel Fernández de Zafra. 5 de septiembre de 1782.

92 A.G.S. Gracia y Justicia, Leg. 825: Relación jurada del estado en que se halla el corregidor de Alcira. Alcira, 2 de diciembre de 1783. 
ron fueran, por lo general, de escasa cualificación. Pese a que hemos detectado algunos problemas con los vecindarios sobre los que ejercían su jurisdicción, éstos fueron de escasa entidad y esporádicos, la mayor parte producto de roces con las oligarquías que controlaban el poder municipal, y su comportamiento sustancialmente distinto del que hacían gala los infatuados y rigorosos corregidores militares, que en lo sustancial siguieron protagonizando el entramado administrativo valenciano hasta la conmoción general de 1808. 